\title{
Vertical crustal motion derived from satellite altimetry and tide gauges, and comparisons with DORIS measurements
}

\author{
R.D. Ray ${ }^{a, *}$, B.D. Beckley ${ }^{b}$, F.G. Lemoine ${ }^{a}$ \\ "NASA Goddard Space Flight Center, Greenbelt, Maryland, USA \\ ${ }^{\mathrm{b}} S G T$, Inc, NASA/GSFC, Greenbelt, Maryland, USA
}

Received 7 Oetober 2009; received in revised form 16 February 2010; accepted 17 February 2010

\begin{abstract}
A somewhat unorthodox method for determining vertical crustal motion at a tide-gauge location is to difference the sea level time series with an equivalent time series determined from satellite altimetry. To the extent that both instruments measure an identical ocean signal, the difference will be dominated by vertical land motion at the gauge. We revisit this technique by analyzing sea level signals at 28 tide gauges that are colocated with DORIS geodetic stations. Comparisons of altimeter-gauge vertical rates with DORIS rates yield a median difference of $1.8 \mathrm{~mm} \mathrm{yr}^{-1}$ and a weighted root-mean-square difference of $2.7 \mathrm{~mm} \mathrm{yr}^{-1}$. The latter suggests that our uncertainty estimates, which are primarily based on an assumed AR(1) noise process in all time series, underestimates the true errors. Several sources of additional error are discussed, including possible scale errors in the terrestrial reference frame to which altimeter-gauge rates are mostly insensitive. One of our stations, Malè, Maldives, which has been the subject of some uninformed arguments about sea-level rise, is found to have almost no vertical motion, and thus is vulnerable to rising sea levels.

Published by Elsevier Ltd. on behalf of COSPAR.
\end{abstract}

Keywords: Vertical land motion; Sea level; Satellite altimetry; DORIS; Tide gauges

\section{Introduction}

The precise measurement of vertical crustal motion is one of the most important, yet highly challenging, tasks of modern geodesy, with applications to a wide range of geophysical problems. The signals are tiny-of order $1 \mathrm{~cm}$ per year or smaller-even for "large" motions such as those associated with Pleistocene ice unloading. The present capability of space geodetic methods to measure vertical motion is discussed by (among others) Altamimi et al. (2007), Collileux et al. (2007) and Rülke et al. (2008).

Determination of vertical land motion at tide gauges is fundamental to the measurement of sea level, be it by tide gauges or by satellite altimetry (Douglas et al., 2001; Woodworth, 2006). For tide-gauge measurements of absolute sea level, knowledge of vertical motion is obviously

\footnotetext{
* Corresponding author.

E-matl address: richard ray@anasa,gov (R.D. Ray).
}

critical. For altimetry the requirement arises through calibration/validation, which is often performed via a global network of tide gauges; insufficiently known vertical motion at the gauges is currently the limiting factor in accurate altimeter validations (Mitchum, 2000). For these reasons the international community has organized large geodetic campaigns that are beginning to provide the necessary data (Schöne et al., 2009; Wöppelmann et al., 2009).

Another approach to recover land motion at tide gauges is to turn the calibration problem around and difference the common sea level time series seen by both the altimeter and the gauges. To the extent the sea level signals are truly common, the difference is a measure of vertical land motion at the gauge. The approach has been explored by Cazenave et al. (1999), Nerem and Mitchum (2002), Garcra et al. (2007), and others. We revisit the problem here because as the time series lengthen we expect some level of improved precision in all estimates, and we now have in hand over sixteen years of high-quality altimetry from 
the Topex/Poseidon (T/P), Jason-1, and Jason-2 satellites. Moreover, the data processing issues are sufficiently complex to warrant several approaches to the problem, and our approach, while fundamentally similar to previous work, is different in some important details. Finally, as part of this special journal issue devoted to the DORIS geodetic system, we take the opportunity to compare recent DORIS-derived vertical rates with our own altimeter-gauge estimates.

\section{Data processing}

In briefest terms our approach is to form near-global gridded arrays of altimetric sea levels every 9.92 days (the repeat period of the satellites) and to extract from these grids sea-level time series near selected tide-gauge locations. The tide gauge data are low-pass filtered to correspond to the signals in the gridded altimetry. Differencing any two such time series gives an estimate of the vertical land motion at the gauge location. The following subsections give further details for each data type.

\subsection{Altimeter data}

We use data from the satellites Topex/Poseidon (Fu et al., 1994), Jason-1 (Ménard et al., 2003), and Jason-2. All data have been collected along the primary $\mathrm{T} / \mathrm{P}$ ground track from September 1992 through March 2009. This time series of altimetry comprises 608 repeat cycles, although some repeats have only partial or no data because of operational issues. In our time series the transition dates between the three satellites are 4 May 2002 and 12 July 2008. Our analysis begins with official project-released versions of the data as follows: T/P from MDGR-B, Jason-1 from GDR-C, and Jason-2 from standards consistent with the Jason-1 GDR-C. We have then updated a number of altimeter correction fields, the most important of which we note below.

A great deal of effort has been expended to ensure the data are as consistent as possible between the different satellites and that both the altimeter ranges and the myriad required corrections are well calibrated and validated. Beckley et al. (2004) describe in some detail the work involved in seamlessly merging $\mathrm{T} / \mathrm{P}$ and Jason-1 data, and similar work has recently been done for Jason-1 and Jason-2 (Beckley et al., 2010). The cross-satellite transitions have been markedly helped by the special tandem-mission calibration campaigns during which the 'old' and 'new' satellites fly in close proximity for several months. On the basis of these near-simultaneous ocean elevation measurements we find a $99 \mathrm{~mm}$ bias between $\mathrm{T} / \mathrm{P}$ and Jason-1 and a $175 \mathrm{~mm}$ bias between $\mathrm{T} / \mathrm{P}$ and Jason-2. (Note that these bias estimates are to some extent functions of range corrections, orbits, and other variables; see, for example, Dorandeu et al. (2004).)

Within-mission calibrations are also critical. For example, the onboard microwave radiometers, necessary to cor- rect altimetric ranges for wet tropospheric delay, have been found prone to drift (Keihm et al., 2000; Ruf, 2000) and are a continuing source of attention (Scharroo et al., 2004; Brown et al., 2004; Zlotnicki and Desai, 2004). We use a recalibrated Topex microwave radiometer replacement product to MGDR-B (Brown et al., 2009) and a Jason-1 microwave radiometer replacement product for GDR-C (Brown et al., 2007). See the cited references for details of the calibration techniques.

We use a completely new set of orbital ephemerides computed for all three satellites by Lemoine et al. (submitted for publication), based on DORIS and laser tracking of the satellites with ground-based tracking stations situated according to the International Terrestrial Reference Frame 2005 (Altamimi et al., 2007). The frame to which our estimated vertical crustal motions refer is a somewhat subtle issue. The altimetric satellites, of course, orbit the center of mass of the whole Earth system and not the center of frame formed by the tracking stations. The orbit determination process partially compensates for the difference, mostly through empirically derived accelerations adjusted to fit the tracking data. The amount of compensation, however, is not always certain; it depends in part on modeling issues involving the geocenter, a topic of current research in orbit determination. In any event, through the tie to the tracking stations the altimetric sea-surface heights will tend to be approximately located within the ITRF2005. The reference frame used for the tracking stations does clearly affect the final sea-surface heights (Morel and Willis, 2002; Morel and Willis, 2005; Beckley et al., 2007), especially in the $Z$ (or northward) direction, but also in orthogonal directions as well. To the extent that the altimetric seasurface heights are located in the ITRF2005, we consider our estimated vertical station motions are also approximately in that frame.

There is, however, one important exception. Altimetric sea levels are mostly immune to scale errors in the reference frame. This was pointed out by Morel and Willis (2005) by experimenting with scale-dependent adjustments to the geodetic stations tracking $\mathrm{T} / \mathrm{P}$, and it has been confirmed in unpublished orbit-determination calculations by our own group. Changing the reference-frame scale may inflate (or deflate) the satellite tracking residuals, but it otherwise leaves the semimajor axis and hence mean sea levelunaffected, the axis being fixed primarily by the satellite orbital period. Thus, our altimeter-gauge vertical land motions are also insensitive to reference-frame scale, in contrast to more direct determinations by geodetic measurements. We return to this point below in the context of comparisons with DORIS.

Because the issue of residual drift in the altimetry is of critical importance to inferred rates of land motion, any additional possible monitoring or estimation of drift is worthwhile. We have therefore subjected our final altimeter time series to the tide-gauge validation procedures described by Mitchum (2000). Prof. Mitchum kindly computed the data shown in Fig. 1, which shows mean 


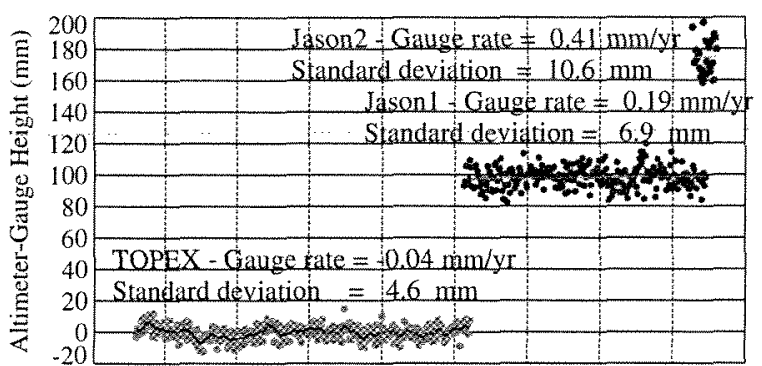

$1992 \quad 1994 \quad 1996 \quad 1998 \quad 2000 \quad 2002 \quad 2004 \quad 2006 \quad 2008 \quad 2010$

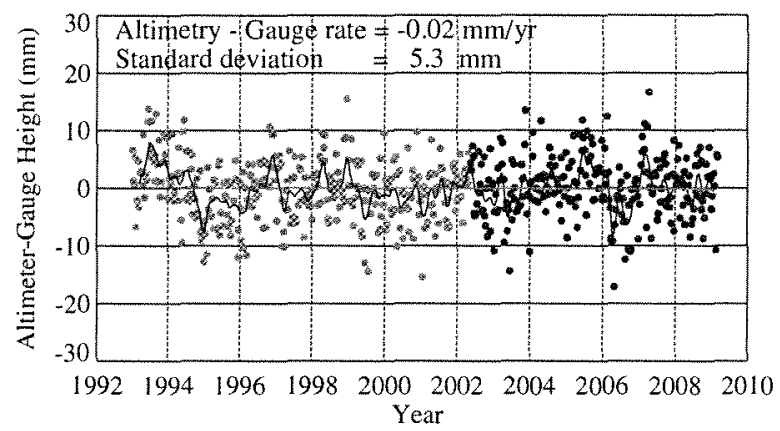

Fig. 1. The results of the altimeter validation procedure computed courtesy of Prof, Gary Mitchum on our final time series of altimetric sea-surface heights. Each dot gives the mean difference ( $\mathrm{mm}$ ) between altimetric and tide-gauge sea levels evaluated at a large array of tide gauges. See Mitchum (2000) for further details, including the procedures used to account for land motion at tide gauges. TOP diagram shows the outputs before we have corrected for inter-satellite bias. BOTTOM diagram shows after correction. Colors denote satellite according to: $\mathrm{T} / \mathrm{P}$ (cyan), Jason-1 (dark blue), Jason-2 (purple)

differences between altimetric and tide-gauge sea levels computed for every $10-\mathrm{d}$ repeat cycle; the top diagram shows the mean differences before correcting for the 99$\mathrm{mm}$ and $175-\mathrm{mm}$ inter-satellite biases, the bottom diagram shows the mean differences after correcting. A linear fit to the bottom data gives a trend of only $-0.02 \mathrm{~mm} \mathrm{yr}^{-1}$. The Mitchum procedure itself is sensitive to reference frame uncertainties and site instabilities, as Mitchum has stressed, but to the extent that the procedure is a valid test for system drift, our data show no drift and moreover show no evidence of any residual bias between missions.

It is important to note that tide gauge comparisons, such as Fig. 1, are used only to test and validate the altimetric heights, not to calibrate them. The altimetry and gauge data remain independent in our analysis.

To form 10-day gridded altimeter sea-surface heights we have found it useful to apply a correction for atmospheric loading, since it removes substantial power at periods below 10 days and thereby reduces noise and improves the consistency of neighboring tracks during the gridding step. For this we used an inverted barometer correction, based on daily mean pressures from NCEP Reanalysis-2 (Kanamitsu et al., 2002) weather products. Daily means are used rather than the more standard 3 -h or 6 -h products because (a) the ocean is manifestly not isostatic at sub-daily frequencies and (b) $S_{2}$ atmospheric tide signals in the higher-frequency pressure data interfere with the tidal correction of altimetry, the models for which already properly account for $\mathrm{S}_{2}$ radiational tides (Ray, 1999).

\subsection{Differencing altimetry and tide gauge data}

All tide gauge data used in this paper are from the archives of the University of Hawaii Sea Level Center. For the main analysis part of the paper, we selected tide gauge stations situated within $150 \mathrm{~km}$ of a DORIS geodetic station, although we also use a few additional gauges to illustrate certain points. We also require the overlap between the altimeter and gauge time series to be at least five years. In our experience shorter segments yield unreliable vertical rates. There are 28 stations satisfying these criteria; their positions are shown in Fig. 2.

We use daily mean sea levels, which are computed at the Hawaii center from hourly data by means of a 119-point convolution filter which has a response of 95,50 , and $5 \%$ at periods of 124,60 , and 40 hours. This essentially eliminates all tidal power in the diurnal and higher frequency bands.

Since we estimate vertical land motion by subtracting the sea levels observed by altimetry and tide gauges, it is essential that the processing of both data types be as consistent as possible. For example, we must correct the tidegauge data for the tides of long period (weekly through $18.6 \mathrm{yrs}$ ), plus the pole tide, with models consistent with those models used for the altimetry. The details of the models need not concern us, nor even their accuracies, since common errors will cancel; it is the consistency of models that must be ensured. Perhaps the most important is allowance for the 18.6-yr node tide, for which we use a self-consistent equilibrium model (Agnew and Farrell, 1978), which can be roughly approximated by a degree- 2 zonal spherical harmonic with amplitudes approximately $8 \mathrm{~mm}$ along the equator and double that at the poles. Neglecting to apply this correction to the tide gauges could, if we are unlucky, induce in a 9-year time series a false trend of about $2 \mathrm{~mm}$ $\mathrm{yr}^{-1}$, or even double that in high latitudes.

Likewise, since an inverted barometer correction was used for altimetry, we applied the identical correction (based on mean daily atmospheric pressures) to the daily tide-gauge data.

Finally, to attempt to match the temporal characteristics of the gridded altimeter data we applied a low-pass filter to all tide-gauge data. The filter has a (broad) cutoff at a period around 25 days.

\subsection{DORIS vertical rates}

A number of groups have processed DORIS data and computed station positions and velocities which could be used to compare against our altimeter-gauge vertical rates. 


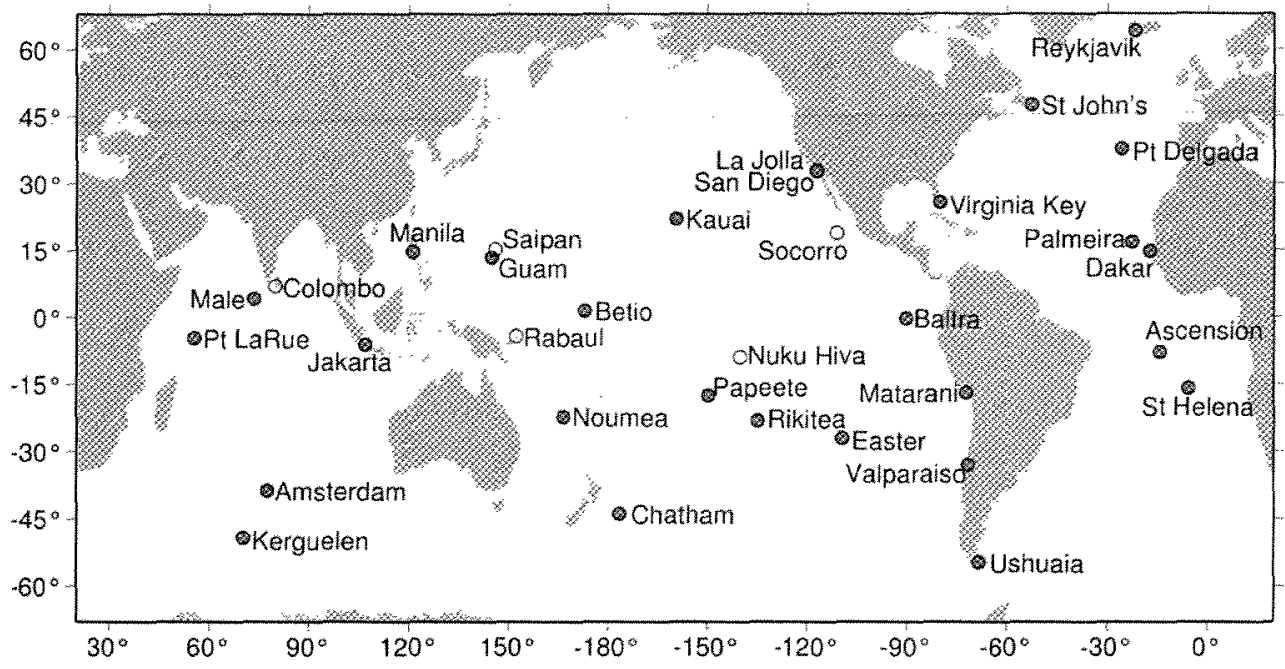

Fig. 2. Locations of tide gauges and DORIS stations used in this study. Unfilled circles are tide gauges referred to in the text but for various reasons (c.g., no nearby DORIS data) are not included in Table 1.

We prefer, however, to use time series of station coordinates, since these can sometimes shed more light on station motion. From a time series of station heights we can compute velocity trends as needed.

In this paper we have employed the recent series solution of P. Willis and colleagues at the Institut Géographique National (IGN), denoted 'ign09wd01.stcd' which consists of weekly estimates of station coordinates (Willis et al., 2010) available from the International DORIS Service (Tavernier et al., 2006). The ign 09 wd 01 solution is a derivative of the solution submitted by the IGN for ITRF2008, and includes updates to the orbit processing for radiation pressure modelling and drag parameterization that improve the station position, geocenter and earth-orientation determination. The IGN series solutions are also essentially equivalent to those earlier described by Gobinddass et al. (2009). DORIS solutions have been produced by other groups as well; three solutions that contributed to the ITRF2005 have been independently assessed by Altamimi et al. (2006). Of the seven DORIS solutions recently submitted to ITRF2008, the Willis et al. (2010) solution is at present the only one available as station-coordinate time series.

From these station coordinate time series we compute vertical velocities, with each weekly point weighted by its formal error. Problematic data flagged by Willis et al. (2009, Table 1) are not used. One delicate point is how to handle multiple occupations at a given site. In such cases it is possible to merge time series by using local geodetic ties, but we have not attempted to do so. Instead we simply compute vertical velocities for each individual occupation and compute a weighted mean of these for our final station velocity estimate. This is emphasized in our time series plots below (e.g., Figs. 9-12) where we display each separate DORIS occupation period with zero mean elevation-i.e., the time series will purposely appear disjointed.

\subsection{Error bars}

All of the altimeter-gauge time series that we have tested fail the widely used Durbin-Watson test for serial correlation (Draper and Smith, 1998), usually with very high significance levels (i.e., more strictly, they fail the null test of no serial correlation). In light of this, throughout this paper whenever we estimate a linear trend from a time series, we account for serial correlation by assuming an order-1 autoregressive AR(1) noise process with the correlation coefficient computed directly from residuals. Such an error model is often adopted in geophysical time series analysis, since red noise processes are so common (Bloomfield and Nychka, 1992, e.g.; von Storch and Zwiers, 1999). A variety of other noise models for DORIS station-coordinate time series have been extensively explored by Williams and Willis (2006), including a model equivalent to AR(1); in fact, the autoregressive model, combined with a variable white noise model (dependent on weekly formal errors in DORIS estimates), was preferred in at least one of their tests, although in the end the authors recommended a modified flicker noise model. Some of their error models (especially the exponential decaying white noise model) are unlikely to apply directly to altimeter and tide-gauge time series, and it is outside the scope of the present paper to investigate in detail the most applicable noise model. Our approach here is to use the AR(1) model as a useful general approximation for handling serial correlation. Lee and Lund (2004) give a brief review of the problem and give useful formulae for confidence intervals which we adopt here.

For the altimeter-gauge vertical rates we attempt to account for one further systematic error, which is the uncertainty in the overall altimeter drift rate as deduced from a Mitchum-type calibration/validation study (Nerem and Mitchum, 2002, ef.). This latter uncertainty was 
thought by Mitchum (2000) to be roughly $0.4 \mathrm{~mm} \mathrm{yr}^{-1}$ stemming primarily from uncertainties in the land motion at gauges. This is generally smaller (often much smaller) than the autoregressive-based standard errors on our estimated vertical rates, but it implies that our altimeter-gauge rates have error bars never less than this adopted value of $0.4 \mathrm{~mm} \mathrm{yr}^{-1}$.

There is a simiar systematic error in our DORIS-based vertical rates which we do not explicitly account for. Because the DORIS weekly positions have already been transformed into the ITRF2005 via 7-parameter transformations, the quoted DORIS uncertainties are in some sense internal measures of those transformations without regard to the underlying errors in the ITRF itself (P. Willis, pers. commun., 2010). For vertical rates the largest errors induced by reference-frame errors arise from uncertainties in the global $Z$ (northward) drift of the frame and in the scale of the frame. Since many of our tide-gauge stations are in low to middle latitudes, the scale may be the more important. Present-day uncertainty in the scale is thought to be of order $0.1 \mathrm{ppb} \mathrm{yr}^{-1}$ ( $\mathrm{Z}$. Altamimi, pers. commun., 2008), which translates to about $0.6 \mathrm{~mm} \mathrm{yr}^{-1}$ in the vertical. This is often larger than our quoted standard errors in DORIS rates, so our quoted errors should be considered somewhat too optimistic. Note that any error in the ITRF scale would affect all DORIS-based vertical rates by precisely the same amount.

All quoted uncertainties below represent $1-\sigma$ standard errors.

\section{Revisiting Cazenave et al. (1999)}

Before turning to a more comprehensive compilation and comparison with DORIS measurements, we revisit a few interesting examples of altimeter-gauge vertical motion estimates which were originally discussed by Cazenave et al. (1999). Those authors called attention to several locations displaying anomalously large vertical rates. The most extraordinary was at Socorro Island, of the western coast of Mexico, where time series of altimeter-gauge differences and weekly DORIS coordinate solutions both showed a very large $\sim 30 \mathrm{~cm}$ subsidence over a span of about three years. This apparently reflected deformation following a volcanic eruption in 1993. Unfortunately, we can add little to their discussion because the tide gauge measurements at Socorro discontinued in Sept. 1997. However, DORIS measurements have continued, and they form the basis for a recent geophysical analysis of Socorro Island by Briole et al. (2009).

Of the other locations of anomalous vertical motion noted by Cazenave et al. (1999), the three largest rates were at Saipan, Nuku Hiva, and Rabaul. None of these three sites had or has DORIS measurements. In Fig. 3 we show an updated time series for Saipan. It is clear that the large vertical motion of $20.0 \pm 2.1 \mathrm{~mm} \mathrm{yr}^{-1}$ noted by Cazenave et al. abruptly stopped just after their paper was published. Since then there has been a slow apparent subsidence, which mostly cancels the earlier rise; a linear fit to the entire time series gives a trend of $0.6 \pm 0.6 \mathrm{~mm} \mathrm{yr}^{-1}$. Cazenave et al. stated that the cause of the observed trend at Saipan was "unclear from a geological point of view," and we concur, especially in light of the observed change in trend. There is no record of any instrument changes around 1997-1998.

At Nuku Hiva the large negative rate noted by Cazenave et al. (1999) appears to have continued (Fig. 4), although the tide gauge time series was interrupted over the interval 1998-2004. At this point we are unsure about the relative datums before and after the interruption, so we have split the figure. Nonetheless, estimated linear trends for both
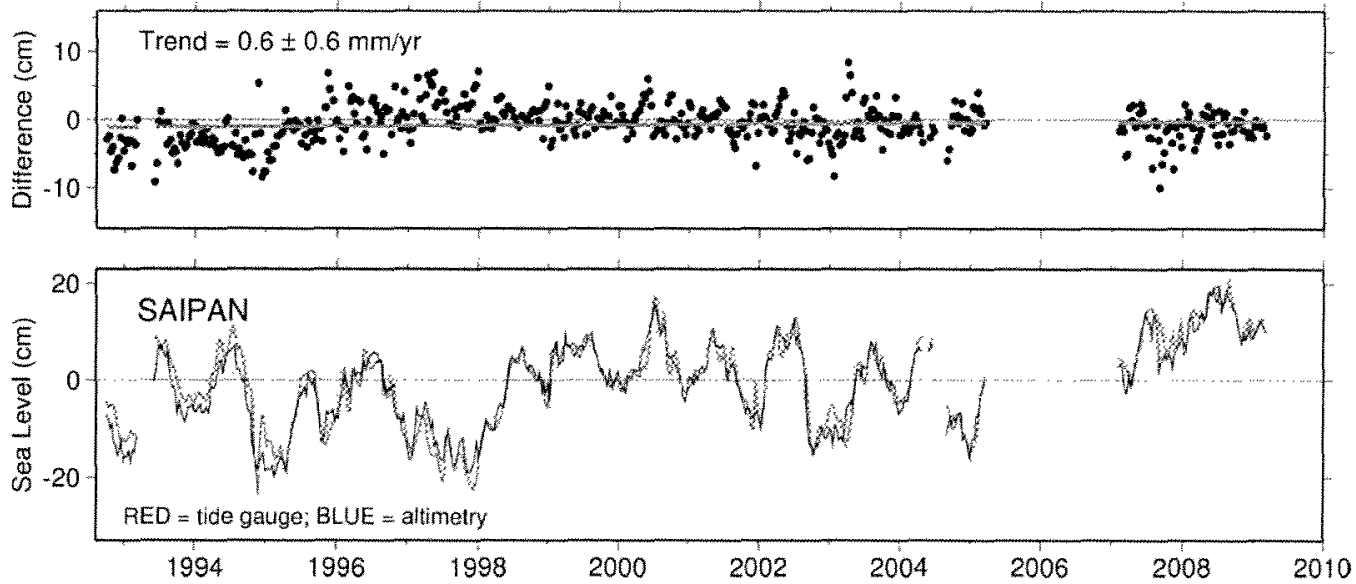

Fig. 3. (Bottom) Altimetric and tide-gauge sea levels at Saipan. Atmospheric loading signals have been removed from both time series by use of an inverted barometer correction based on daily mean atmospheric pressures. (Top) Differences betwcen altimetric and tide-gauge sea level time series, each point representing a 10-d estimate. To the extent that the altimeter and the tide gauge observes identical sea-surface elevations, then the difference (altimeter minus gauge) is a proxy for vertical position of the tide gauge. Cazenave et al. (1999) called attention to the high vertical rate at Saipan during the 1992-1997 time period, but that rate abruptly stops thereafter. Fitted linear trend (magenta linc) is for the cntire time series. 

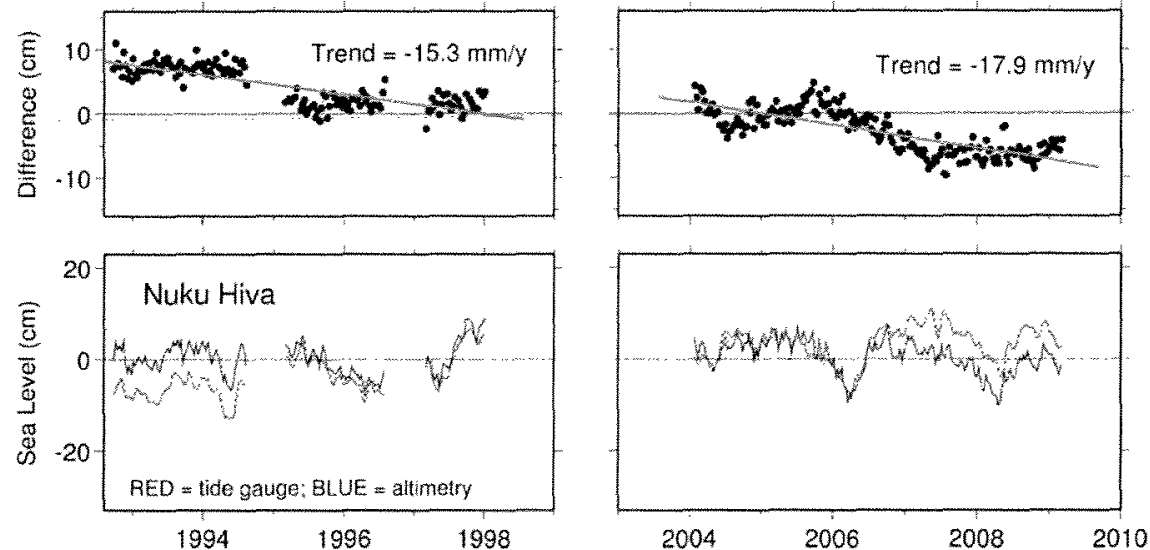

Fig. 4. Altimetric and tide-gauge sea levels at Nuku Hiva (bottom) and their differences (top), a proxy for vertical position of the tide gauge. Tide gauge measurements were interrupted over the interval 1998-2004.

sections of the time series are comparable, but if we assume continuity we find a trend for the entire series significantly lower: $-7.1 \pm 2.7 \mathrm{~mm} \mathrm{yr}^{-1}$. Moreover, the early section might be better explained as nearly constant (zero trend) but with one discontinuity sometime when the time series was interrupted near beginning 1995; the later section after 2004 is more complicated.

At Rabaul we again have no further tide gauge data than those employed by Cazenave et al. (1999). However, in this case our Fig. 5 is not so much an update to their figure as it is a correction in light of better documentation. As Cazenave et al. noted, a series of volcanic events in late 1994 caused significant subsidence at the Rabaul tide gauge. This information was reported by the Rabaul Volcanological Observatory to the Hawaii Sea Level Cen-
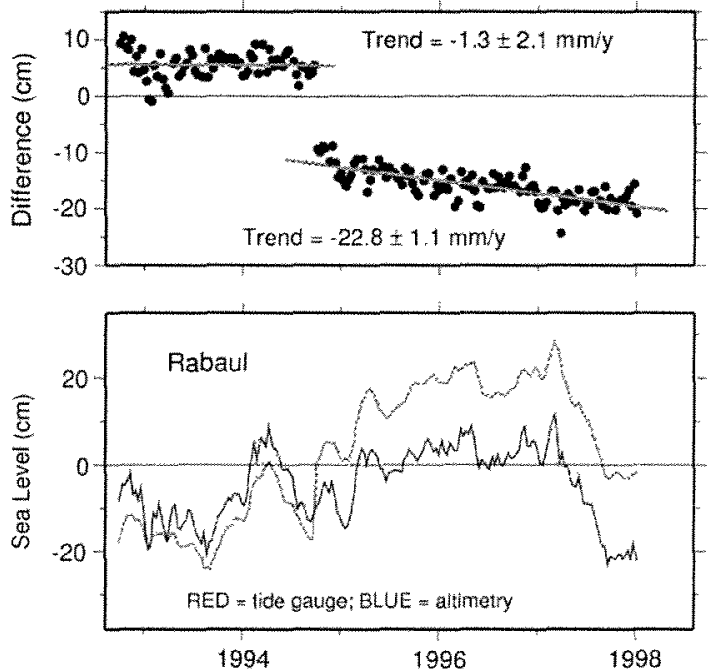

Fig. 5. Altimetric and tide-gauge sea levels at Rabaul (bottom) and their differences (top), a proxy for vertical station position. The large discontinuity in early October 1994, representing subsidence of over $15 \mathrm{~cm}$, followed a series of nearby volcanic eruptions. Large, roughly linear, subsidence continues for several more years until the tide-gauge data stop. ter and the tide gauge data were subsequently adjusted by $-13 \mathrm{~cm}$ in October 1994 and by $-14 \mathrm{~cm}$ in November 1994 and thereafter (Patrick Caldwell, pers. commun., 2009). Thus, the Rabaul inferred land motion in Fig. 6 of Cazenave et al. (1999) is much smoother than it should have been. If we "uncorrect" the data (our Fig. 5) we see the large jump $(\sim 15 \mathrm{~cm})$ reported by the Rabaul personnel. In addition, a large, roughly linear, subsidence continues for several more years until the tide-gauge data stop.

In the spirit of Cazenave et al. (1999), we here report a recent unusual implied land motion (or possible tide-gauge problem) at Colombo, Sri Lanka - see Fig. 6. The altimeter-gauge differences display a large jump sometime in the spring of 2006. To our knowledge there were no significant earthquakes in that region during that time, so the time series may well indicate some instrumental problem. The DORIS time series at Colombo was discontinued in
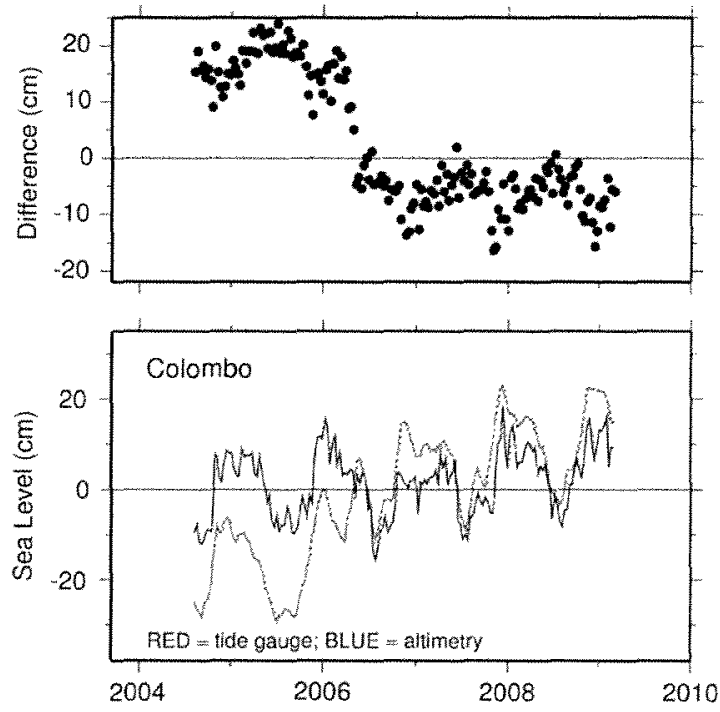

Fig. 6. Altimetric and tide-gauge sea levels at Colombo, Sri Lanka (bottom) and their differences (top). 
October 2004, owing to siting difficulties, so DORIS data can shed no light on this issue.

In the time series data for our 28 primary stations we have noticed a few cases of similar changes in datum level, although none so dramatic as at Colombo. To the extent that these can be reliably recognized we try to account for them in any trend estimates. Our experience suggests (see also discussion below) that further efforts to unravel these possible datum problems, as well as to improve tide-gauge documentation, would be a worthy endeavor.

\section{Estimated vertical rates and comparisons with DORIS}

The estimated vertical rates at our 28 selected tide-gauge stations and at the corresponding DORIS stations are tabulated in Table 1. The altimeter-gauge and DORIS rates are more directly compared in Fig. 7 . From the table and the diagram it is readily apparent that the altimeter-gauge error bars tend to be larger than the DORIS error bars. The median error bar is $1.30 \mathrm{~mm} \mathrm{yr}^{-1}$ for the altimetergauge data, but $0.54 \mathrm{~mm} \mathrm{yr}^{-1}$ for the DORIS data. The spread in the altimeter-gauge vertical rates is also greater, perhaps reflecting the larger error bars. By happenstance most DORIS rates are small, and only three stations have rates near or exceeding $5 \mathrm{~mm} \mathrm{yr}^{-1}$.

The dotted line in Fig. 7 represents a linear fit to all 28 points. Although the error bars in the DORIS estimates are mostly small, they are not zero, so we have used an "errorsin-variables' type regression that allows for errors in both variables (Madansky, 1959; Lybanon, 1984). The slope is $0.92 \pm 0.11$ and the intercept is $-1.12 \pm 0.26 \mathrm{~mm} \mathrm{yr}^{-1}$ (an ordinary least squares regression that ignores errors in the DORIS data yields a biased slope of only 0.60 ). The weighted coefficient of correlation is 0.56 , where we have weighted each point by the reciprocal sum of squares of the individual $x$ and $y$ error bars. The significance of this

Table 1

Estimated vertical crustal motions from altimeter-gauge and DORIS (ign09wd01) data.

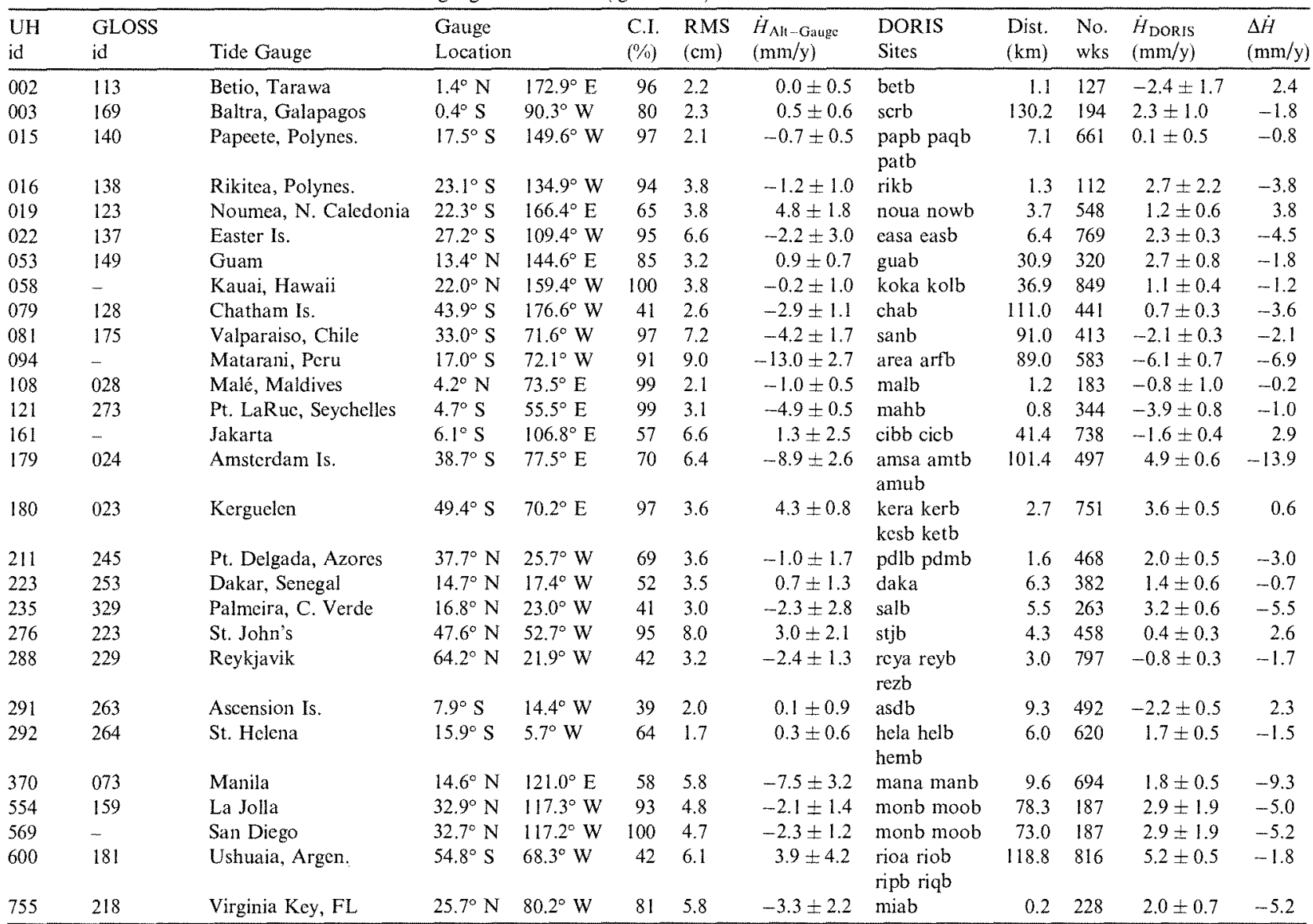

C.I. = Completeness Index, denoting percent of gauge data available in 1993-2009 (after any edits).

RMS = root-mean-square difference between altimetry and gauge data.

Dist. = distance between DORIS station and tide gauge.

No. $w k s=$ number of wcekly DORIS solutions available at this site.

$\Delta \dot{H}=$ difference in altimeter-gauge and DORIS vertical rates. 


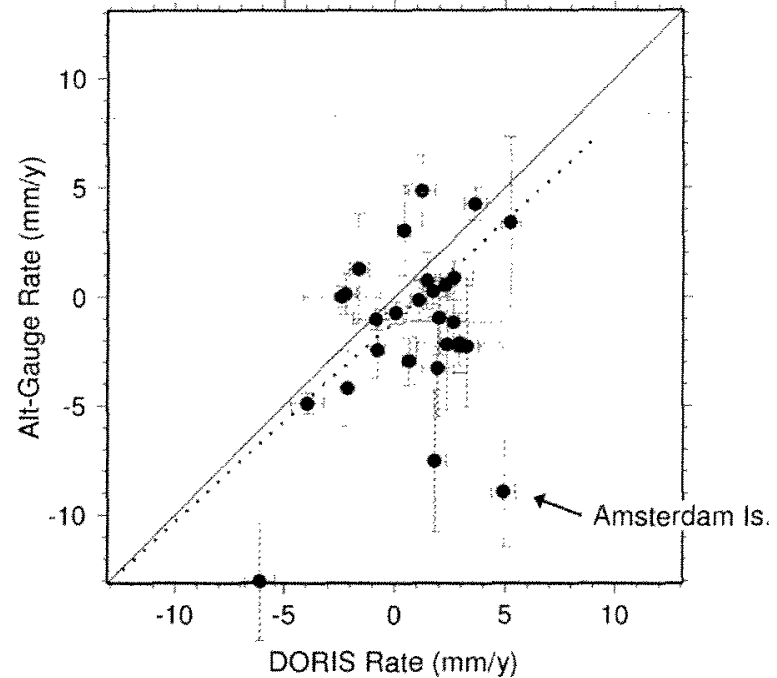

Fig. 7. Scatter diagram comparing estimated vertical land motion rates from our altimeter-gauge analyses with those inferred from DORIS solution 'ign09wd01.sted'. The dotted line is an 'errors-in-variables" regression fit to the data, with slope $0.92 \pm 0.11$ and intercept $-1.12 \pm$ $0.26 \mathrm{~mm} \mathrm{yr}^{-1}$. Amsterdam Island is seen to be a case of particularly poor agreement between the two kinds of vertical-rate estimates; see Fig. 10.

correlation exceeds $99 \%$ according to results of a permutation test, a standard resampling technique for testing statistical significance (Good, 2009).

For all 28 stations the RMS difference between altimeter-gauge and DORIS vertical rates, weighted according to the individual station standard error estimates, is 2.7

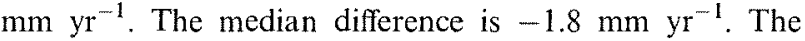
reduced $\chi^{2}$ statistic is 3.6 , large enough to suggest that our vertical-rate standard errors are underestimated, a point anticipated in our discussion in Section 2.4. In fact, of the 28 differences between altimeter-gauge and DORIS vertical rates, 19 exceed the range of the associated quoted errors, far more than should be expected. If we arbitrarily inflate all error bars by $50 \%$, then 10 exceed the range, which is closer to the expected number for $1-\sigma$ standard errors.

A close examination of Table 1 reveals that several of the stations showing poor agreement between altimetergauge and DORIS rates should not be considered truly colocated. For example, the DORIS station at Arequipa, Peru, is located $89 \mathrm{~km}$ from the tide gauge at Matarani, but more importantly it is in the Andes at elevation $2450 \mathrm{~m}$. In such a tectonically active region we cannot expect any consistency in vertical motion. Indeed, in the case of Arequipa we have the additional difficulty of a large earthquake occurring on 23 June 2001, which produced a vertical offset of several $\mathrm{cm}$ and at least a temporary change in velocity (Melbourne et al., 2002; Willis et al., 2009). (For this reason we had already removed the 'areb' occupation, corresponding to the period 2002.0-2003.6, from our tabulation; the pre-earthquake 'area' and post-earthquake ' $a r f b$ ' occupations do yield consistent vertical rates.)
Similar points can be made for the distance between Monument Peak and the tide gauges at San Diego and La Jolla.

If we limit the tide gauge and DORIS station separation to $6 \mathrm{~km}$ we find many of the discrepant stations in Fig. 7 drop out. Fig. 8 shows the revised scatter plot, now with 14 points. The slope of the fitted line is $1.11 \pm 0.16$ and the intercept is $-0.78 \pm 0.39$. The weighted coefficient of correlation is now increased to 0.78 . For these 14 stations the RMS difference between altimeter-gauge and DORIS estimates drops to $2.0 \mathrm{~mm} \mathrm{yr}^{-1}$ and the median difference is $-1.2 \mathrm{~mm} \mathrm{yr}^{-1}$

Although these kinds of statistical summaries are useful, it is enlightening to examine the individual time series. Space precludes a presentation of all 28 , so we instead focus on four examples. Of these, two correspond to significantly non-zero vertical rates, one being a 'good' example (it lies approximately along the unit-slope line of Fig. 7) and the other a 'bad' example (far from the line). These are shown in Figs. 9 and 10, respectively.

The Amsterdam Island example (Fig. 10) shows mediocre agreement between the altimetric and tide-gauge sea levels, with a correlation coefficient of only 0.50 and an RMS difference of $6.4 \mathrm{~cm}$. There is also a strong suggestion of a change in slope near the data gap in 1999. Clearly if the altimeter and tide gauge are failing to observe a common sea-level signal, then any inference about vertical land motion is suspect. That appears to be the case here.

Nonetheless, the altimeter-gauge differences in Fig. 10 do suggest a large negative trend, so the disagreement with the DORIS-based trend of $+4.9 \pm 0.6 \mathrm{~mm} \mathrm{yr}^{-1}$ is all the more striking. Note, however, the DORIS estimate is dominated mostly by the second occupation (amtb); the rate from more recent data (amub) is much smaller. An early

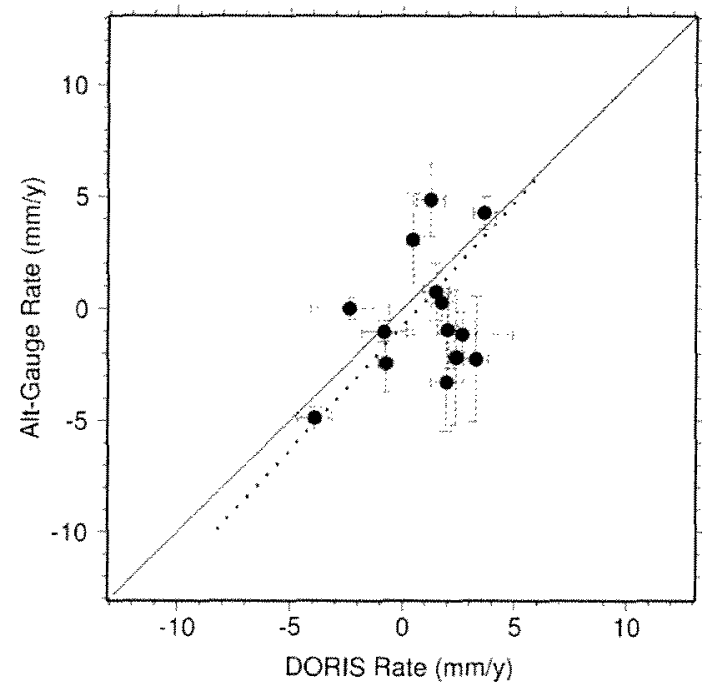

Fig. 8. As in Fig. 7, except using only those points where the DORIS ground station is within $6 \mathrm{~km}$ of the tide gauge. The dotted line is an 'errors-in-variables' regression fit to the data, with slope $1.11 \pm 0.16$ and intercept $-0.78 \pm 0.39$. 

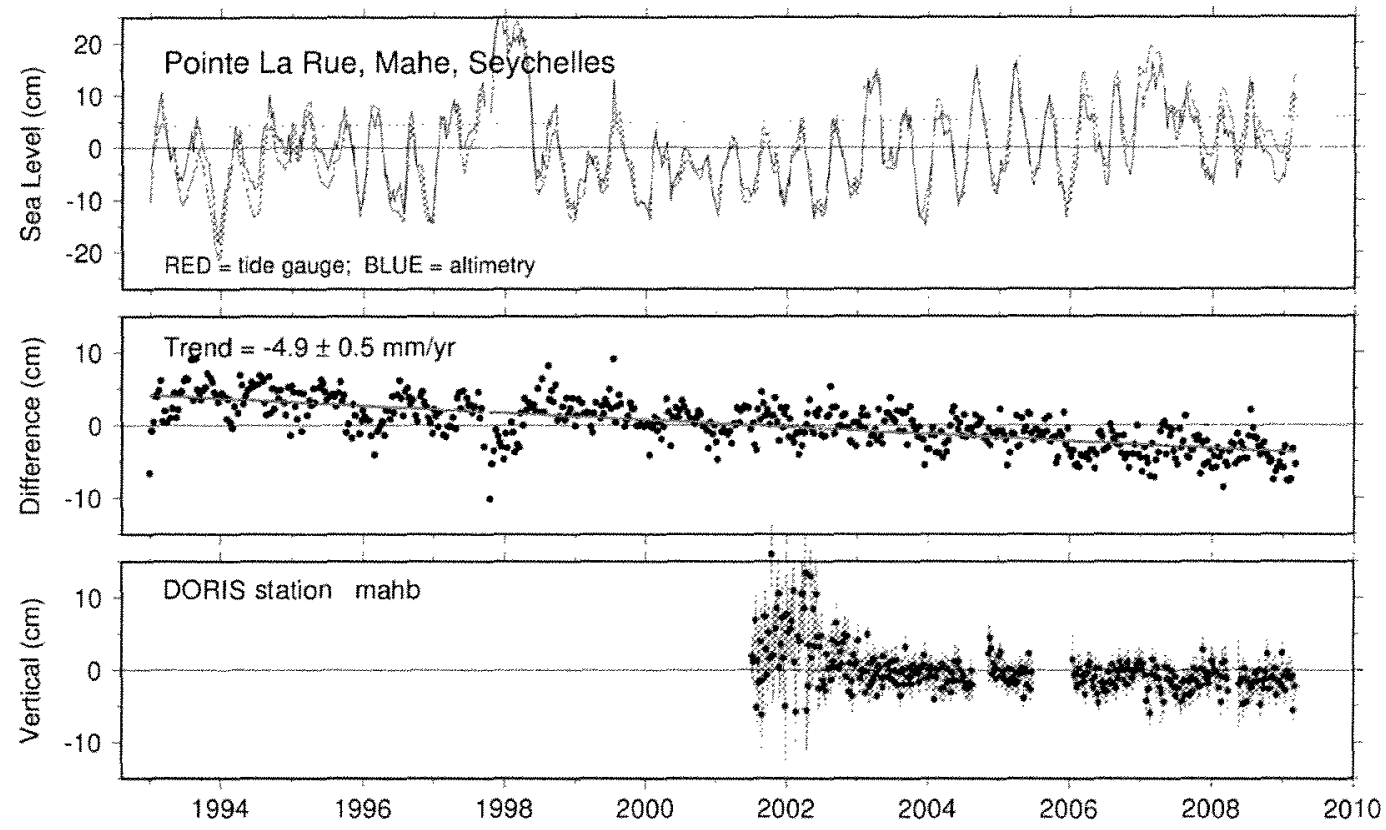

Fig. 9. (Top) Altimetric and tide-gauge sea levels at Point La Rue in the Seychelles. The correlation between the two curves is 0.92 . (Middle) Ten-day differences between the two time series shown in the top panel, a proxy for vertical position of the tide-gauge station. (Bottom) Time series of weekly vertical coordinates from DORIS solution ign09wd01.sted. The precision of these estimates increases with time as more DORIS satellites become available. A least-squares fit to the DORIS data gives a linear trend of $-3.92 \pm 0.77 \mathrm{~mm} \mathrm{yr}^{-1}$.
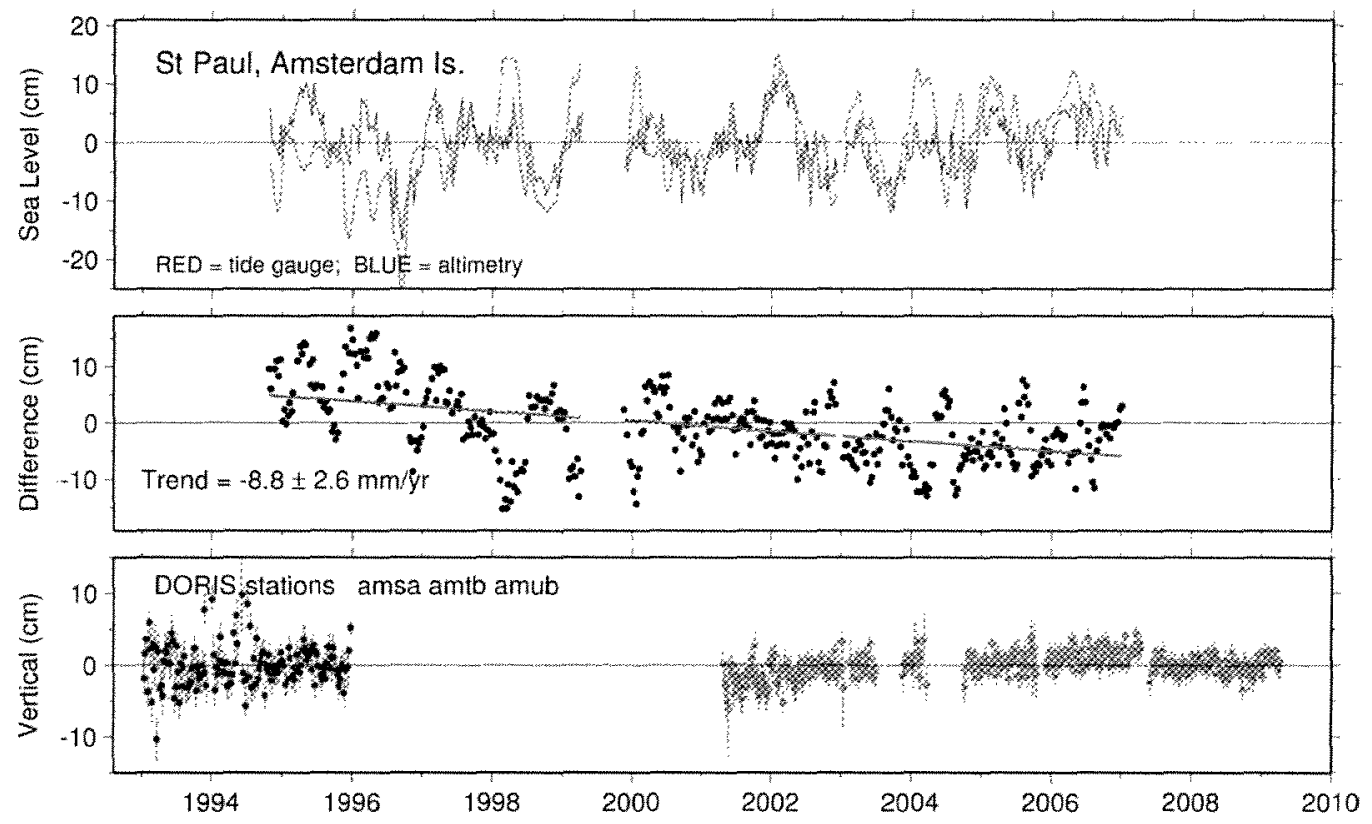

Fig. 10. As in Fig. 9, but for Amsterdam Island in the South Indian Ocean. Different colors in the bottom pancl denote different DORIS occupations; each occupation is separately demeancd, so apparent discontinuities between different occupations may not be real. The DORIS data yield a linear trend of $+4.93 \pm 0.55 \mathrm{~mm} \mathrm{yr}^{-1}$, based primarily on occupation amtb (magenta color). The DORIS and altimeter-gauge vertical-rate estimates are in poor agreement, possibly owing to the poor agreement between altimetric and tide-gauge sea levels.

DORIS solution by Soudarin et al. (1999) found a vertical rate of $-12.5 \mathrm{~mm} \mathrm{yr}^{-1}$. Although this is much closer to our altimeter-gauge rate, it is surely obsolete, being based on fewer DORIS satellites than those now available. Moreover, Willis et al. (2009) point out that the Amsterdam DORIS station has been affected by several antenna tilt 
instabilities. The time periods of these antenna problems are not precisely known, but it does imply that some periods reflect antenna motion rather than land motion. This problem was not discovered until after the Soudarin et al. (1999) study, so antenna motion may have contributed to their large negative rate. Overall, however, we attribute the poor agreement between DORIS and altimeter-gauge rates at Amsterdam Island to the apparent inability of our altimeter signal to reproduce the gauge signal (or vice-versa). Mitchum (2000) also points to "poor ocean signal agreement" at this location, and for this reason he routinely deletes this tide gauge from his altimeter validation tests.

Kerguelen Island (Fig. 11) is another problematic site. Mitchum (2000) again points to a "possible tide gauge level shift." From our altimeter-gauge difference time series (middle panel) we agree that around 1998 there is a fairly clear discontinuity in level, and also in trend. If we fit a trend to only the post-1998 data (which we have done in Table 1) then we find good agreement with the DORISbased rate of $+3.6 \pm 0.5 \mathrm{~mm} \mathrm{yr}^{-1}$.

The tide gauges at both Amsterdam Island and Kerguelen Island are in fact bottom-pressure recorders, which are prone to drift over time (e.g., Woodworth et al., 1996). The Kerguelen deployments are described in some detail by Testut et al. (2006), and those authors summarize various efforts made to determine the drift in the instruments. Over the period shown in our Fig. 11, four successive pressure sensors have been installed in the same stilling well. The first was installed in 1993 and replaced in 1998, which is the point in time we detect a change in slope. Other replacements occurred in 2001 and 2004. The difficulties in recovering system offsets and drifts are emphasized by Testut et al. As our figure suggests, it may well be that satellite altimetry can help in these efforts.

Finally in Fig. 12 we show data from Malé in the Maldives Islands, a chain of low-lying coral islands southwest of India. As can be seen, the agreement between altimetry and tide gauge is very good; the RMS difference is $2.1 \mathrm{~cm}$ and the correlation coefficient is 0.89 . The altimeter-gauge and DORIS vertical land rates are in good agreement, both near zero but negative, suggesting either no vertical movement or very slight subsidence. These results thus add further weight to the evidence, summarized by Woodworth (2005), that the Maldives are unlikely to escape the consequences of ongoing and future sea level rise. That there should be any question in the matter stems from some illinformed arguments made mostly, but not completely, in the popular media (see criticisms by Kench et al., 2005). It seems clear that the low-lying Maldives are in a vulnerable position regarding sea level rise.

\section{Discussion and conclusions}

As Cazenave et al. (1999) and Nerem and Mitchum (2002) noted previously, the use of combined satellite altimeter and tide-gauge data offers a valid and encouraging approach to the problem of determining vertical motion at tide-gauge sites. While the more straightforward geodetic approaches based on DORIS and GPS network
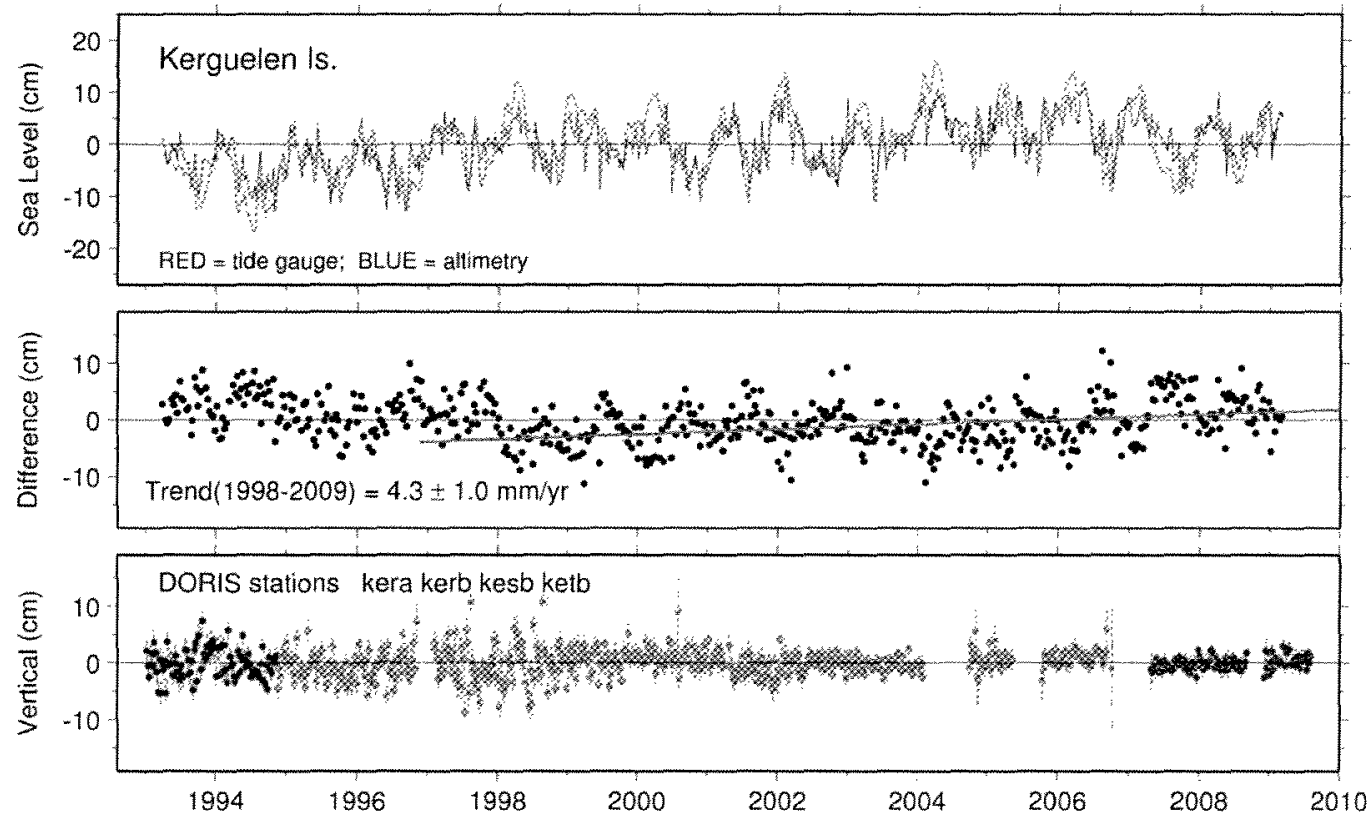

Fig. 11. As in Fig. 10, but for Kerguelen Island. The fitted trend (red line) to the altimeter-gauge differences is based on only the post-1998 data. The DORIS data yeld a linear trend of $+3.63 \pm 0.51 \mathrm{~mm} \mathrm{yr}^{-1}$. Each DORIS occupation is separately demeaned when shown in the bottom panel. 

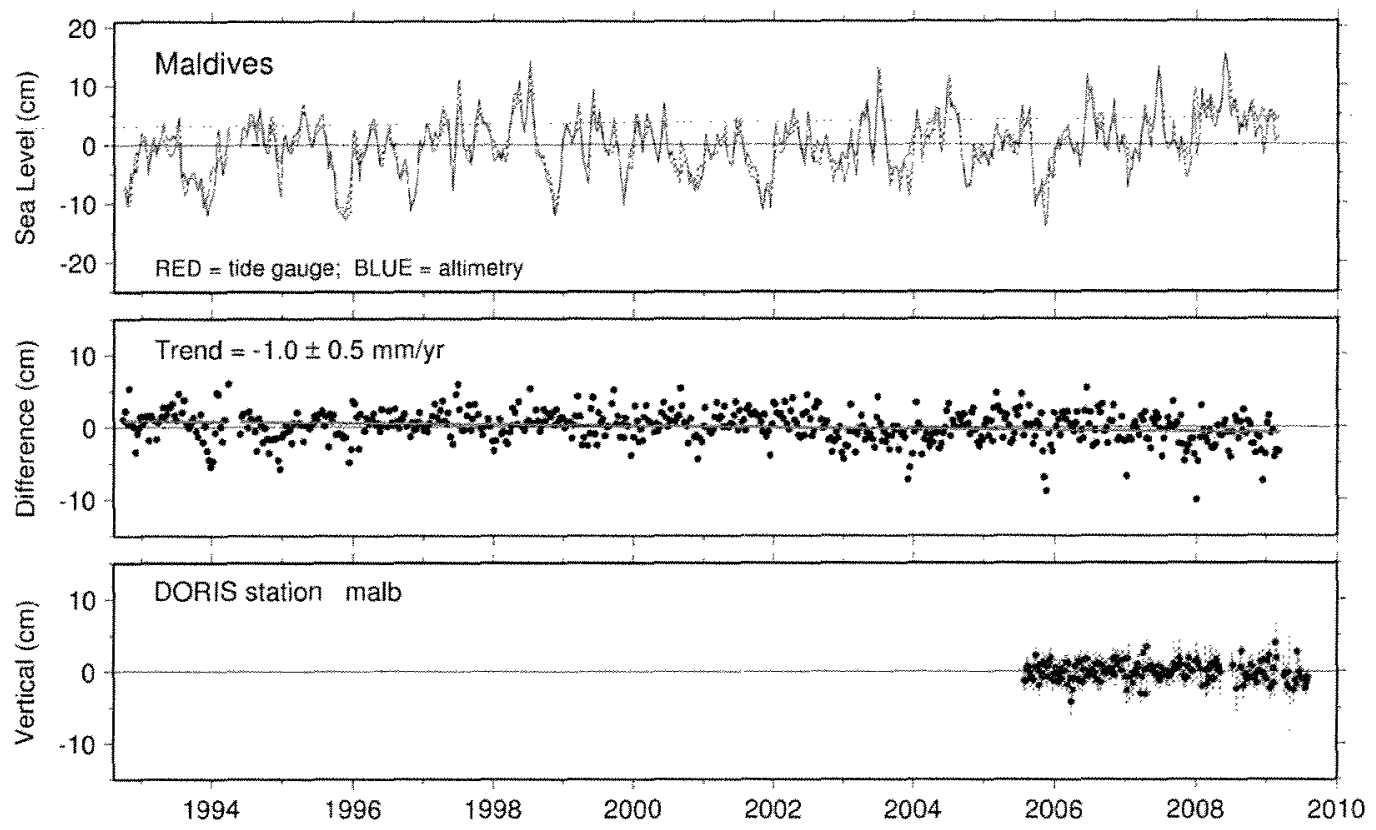

Fig. 12. As in Fig. 9, but for Malè in the Maldives Islands, southwest of India. A least-squares fit to the DORIS data gives a linear trend of $-0.8 \pm 1.0 \mathrm{~mm}$ $\mathrm{yr}^{-1}$. Thus, both altimeter-gauge and DORIS estimates of vertical motion suggest that the Maldives Islands are stable over this time period, or even slightly subsiding.

solutions are becoming more mature, the consistencies of those solutions are not always satisfactory. The altimetergauge approach may thus add some useful information to these analyses.

As noted above, potentially useful information could stem from the general independence of the altimeter-gauge rates from scale errors in the terrestrial reference frame. Both the intercept estimates from Figs. 7 and 8 and the median differences between altimeter-gauge and DORIS vertical rates suggest a systematic global difference of roughly $1 \pm 0.5 \mathrm{~mm} \mathrm{yr}^{-1}$, with DORIS measuring higher rates. A rather large error of order $0.2 \mathrm{ppb} \mathrm{yr}^{-1}$ in the scale of ITRF2005 could explain this, but we are not inclined to push such a conclusion. Our large uncertainty, sometimes stemming from inconsistent altimetric and tide-gauge sealevel curves, the relatively large scatter in Figs. 7 and 8, and problems such as those highlighted for Amsterdam Island, all urge caution. Precisions in the altimeter-gauge vertical rates need to be improved before more definite statements can be made, but they clearly show potential.

It is not surprising that the best altimeter-gauge rate estimates - best in terms of standard error of the estimate as well as agreement with DORIS-are generally for those tide gauges on small open-ocean islands (Easter Island and Amsterdam Island are the exceptions to this). The island data show the best agreement between altimetric and tide-gauge sea level signals; see the RMS values listed in Table 1. Consistency in these two signals is, of course, desirable since the whole technique relies on the altimetry and the tide gauge seeing a common ocean signal.
It is also not surprising that the largest RMS differences between altimetry and gauges occur for those stations along the coasts of large land masses. In contrast to the deep ocean, shelf and near-coastal ocean processes tend to display much shorter wavelengths, a fact that almost ensures the altimeter and gauge are observing somewhat different signals, especially since at some gauges the distance to the nearest altimeter track can be over $200 \mathrm{~km}$. Moreover, the altimetry can be impacted by a number of problems near the coast, including land contamination in the altimeter footprint and, more commonly, in the radiometer footprint and inaccurate environmental corrections, including tides.

Fortunately, this suggests a path toward some progress, since the improvement of shallow-water satellite altimetry is an ongoing concern of several research groups (Vignudelli et al., 2005, e.g.; Bouffard et al., 2008; Vignudelli et al., 2010). Some of this work involves merging data from multiple satellites to obtain the higher spatial resolutions needed in coastal zones. This is clearly desirable, but it will require more complex validation techniques to ensure the integrity of long-period signals, since some satellite altimeters are designed for studying mesoscale phenomena, not subtle climatic signals (or vertical motion signals, as in the present case). In any event, this ongoing work aims to improve all satellite data through improved waveform processing and better corrections, so it should be immediately applicable to studies such as ours.

In addition to the study of crustal motion, the comparison of satellite altimeter and tide-gauge data has the 
potential to reveal unknown problems in the latter. We noted several cases where the gauge data are either problematic or insufficiently documented. See aso the discussion by Mitchum (2000) in this regard.

Vertical crustal motion is one of the most challenging of geodetic measurements. Comparisons of new vertical rates from colocated GPS, DORIS, and other geodetic systems is one of the most important aspects of improving the terrestrial reference frame. More comprehensive and updated analyses of satellite altimetry and tide gauge data are warranted for the insight they can lend to these problems.

\section{Acknowledgements}

We thank Pascal Willis, David Rowlands, and Patrick Caldwell for useful discussions and suggestions. Gary Mitchum calculated the results shown in Fig. 1. Tide gauge data were obtained from the University of Hawaii Sea Level Center. DORIS solutions were made available through the International DORIS Service. Satellite altimeter data were made available through JPL PODAAC and AVISO. This work was supported by the U.S. National Aeronautics and Space Administration under the IDS Sea Level and MEaSUREs programs.

\section{References}

Agnew, D.C., Farrell. W.R. Self-consistent equilibrium ocean tides. Geophys. J. Royal Astro. Soc. 55, 171-182, 1978.

Altamimi, Z. Collilieux, X., Boucher, C. DORIS contributions to ITRF2005. J. Geod. 80, 625-635, 2006.

Altamimi, Z., Collilieux, X., Legrand, J., Garayt, B., Boucher, C. ITRF2005: A new rclease of the International Terrestrial Reference Frame based on time series of station positions and earth orientation parameters. J. Geophys. Res. 112, B09401, 2007.

Beckley, B.D., Zelensky, N.P., Luthcke, S.B., Callahan, P.S. Towards a seamless transition from Topex/Poseidon to Jason-1. Marine Geod. 27, 373-389, 2004.

Beckley, B.D., Lemoine, F.G., Luthcke, S.B., Ray, R.D., Zelensky, N.P. A reassessment of global and regional mean sea level trends from Topex and Jason-1 altimetry based on revised reference frame and orbits. Geophys. Res. Lett. 34, L14608, 2007.

Beckley, B.D. Zelensky, N.P., Holmes, S.A., Lemoine, F.G., Ray, R.D, Mitchum, G.T., Desai, S., Brown, S.T. Assessment of the Jason-2 extension to the Topex/Poseidon, Jason-1 sea-surface height time series for global mean sea level monitoring. Mar. Geodesy, in press, 2010.

Bloomfield, P., Nychka, D. Climate spectra and detecting climate change. Clim. Change 21, 275-287, 1992

Bouffard, J., Vignudelli, S., Cipollini, P., Menard, Y. Exploiting the potential of an improved multimission altimeter data set over the coastal ocean. Geophys. Res. Lett. 35, L10601, 2008.

Briole, P., Willis, P., Dubois, J., Charade, O. Potential volcanological applications of the DORIS system: a geodetic study of the Socorro Island (Mexico) coordinate time series. Geophys. J. Int. 178, 581-590, 2009.

Brown, S.T., Ruf, C., Keihm, S., Kitiyakara, A. Jason nicrowave radiometer performance and on-orbit calibration. Marine Geod. 27, 199-220, 2004.

Brown, S.T., Desai, S., Lu, W., Tanner, A.B. On the long-term stability of microwave radiometers using noise diodes for calibration. IEEE Trans. Geosci. Remote Sens. 45, 1908-1920, 2007
Brown, S.T., Desai, S., Keihm, S., Lu, W. Microwave radiometer calibration on decadal time scalcs using on-earth brightness temperature references: application to the Topex microwave radiometer, J Atmos. Oceanic Tech. 26, 2579-2591, 2009

Cazenave, A., Dominh, K., Ponchaut, F., Soudarin, L., Cretaux, J.F., Lc Provost, C. Sea level changes from Topex-Poseidon altimetry and tide gauges, and vertical crustal motions from DORIS. Geophys. Res. Lett. 26, 2077-2080, 1999.

Collileux, X., Altamimi, Z., Coulot, D., Ray, J., Sillard, P. Comparison of very long baseline interferometry, GPS, and satellite laser ranging height residuals from ITRF2005 using spectral and correlation methods. J. Geophys. Res. 112, B12403, 2007.

Dorandeu, J., Ablain, M., Faugere, Y., Mertz, F., Soussi, B., Vineent, P. Jason-1 global statistical evaluation and performance assessment: calibration and cross-calibration results. Marine Geod. 27, 345-372, 2004.

Douglas, B.C., Kearncy, M.S., Leatherman, S.P. (Eds.). Sea level rise: history and consequences. Academic Press, San Diego, 2001.

Draper, N.R., Smith, H. Applied Regression Analysis, 3rd ed WileyInterscience, 1998

Fu, L.L., Christensen, E.J., Yamarone, C.A., et al. TOPEX/Poseidon mission overview. J. Geophys. Res. 99, 24369-24381, 1994.

Garcia, D., Vigo, I., Chao, B.F., Martinez, M.C. Vertical crustal motion along the Mediterranean and Black Sea coast derived from ocean altimetry and tide gauge data. Purc Appl. Geophys. 164, 851-863, 2007.

Gobinddass, M.L., Willis, P., de Viron, O., Sibthorpe, A., Zelensky, N.P., Ries, J.C., Ferland, R., Bar-Sever, Y.E., Diament, M. Systematic biases in DORIS-derived geocenter time series related to solar radiation pressure mis-modeling. J. Geod. 83, 849-858, 2009.

Good, P.I. Permutation, Parametric, and Bootstrap Tests of Hypotheses Springer, 2009.

Kanamitsu, M., Ebisuzaki, W., Woollen, J., et al. NCEP-DOE AMIP-1I Reanalysis (R-2). Bull. Amer. Meteor. Soc. 83, 1631-1643, 2002.

Keihm, S.J., Zlotnicki, V., Ruf, C.S. TOPEX microwave radiometer performance evaluation, 1992-1998. IEEE Trans. Geosci. Remote Sens. 38, 1379-1386, 2000

Kench, P.S., Nichol, S.L., McLean, R.F. Comment on "New perspectives for the future of the Maldives" by Mörner et al. Global Planet. Change $47,67-69,2005$

Lce, J., Lund, R. Revisiting simple lincar regression with autocorrelated errors. Biometrika 91, 240-245, 2004.

Lemoine, F.G., Zelensky, N.K., Chinn, D.S., et al. Towards development of a consisent orbit series for Topex/Poseidon, Jason-1, and Jason-2. Adv. Space Res., submitted for publication.

Lybanon, M. A better least-squares method when both variables have uncertainties. Amer. J. Phys. 52, 22-26, 1984.

Madansky, A. The fitting of straight lines when both variables are subject to error. J. Amer. Statist. Assoc. 54, 173-205, 1959

Melbournc, T.I., Webb, F.H., Stock, J.M., Reigber, C. Rapid postseismic transients in subduction zones from continuous GPS. J. Geophys. Res. 107 (B10), 2241, 2002

Ménard, Y., Fu, L.-L,, Escudier, P., ct al. The Jason-1 mission. Marine Geod. 26, 131-146, 2003.

Mitchum, G.T. An improved calibration of satellite altimetric heights using tide gauge sea levels with adjustment for land motion. Marine Gcod. 23, 145-166, 2000.

Morel, L., Willis, P. Parameter sensitivity of TOPEX orbit and derived mean sea level to DORIS stations coordinates. Adv. Space Res. 30, $255-263,2002$

Morel, L., Willis, P. Terrestrial reference frame effects on global sea level rise determination from Topex/Poseidon altimetric data. Adv. Space Res. 36, 358-368, 2005.

Nerem, R.S., Mitchum, G.T. Estimates of vertical crustal motion derived from differences of Topex/Poseidon and tide gauge sea level measurcments. Geophys. Res. Lett. 29, 1934, 2002.

Ray, R.D. A global ocean tide model from Topex/Poseidon altimetry: GOT99. NASA Tech. Memo. 209478, 58pp., 1999. 
Rülke, A., Dietrich, R., Fritsche, M., Rothacher, M., Steigenberger, P. Realization of the terrestrial reference systen by a reprocessed global GPS network. J. Gcophys. Res. 113, B08403, 2008.

Ruf, C.S. Detection of calibration drifts in spaceborne microwave radiometers using a vicarious cold reference. IEEE Trans. Geosci. Remote Sens. 38, 44, 2000.

Scharroo, R., Lillibridge, J., Smith, W. Cross-calibration and long-term monitoring of the microwave radiometers of ERS, TOPEX, GFO, Jason, and Envisat. Marine Geod. 27, 279-297, 2004.

Schöne, T., Schön, N., Thaller, D. IGS tide gauge benchmark monitoring pilot project (TIGA): scientific benefits. J. Geod. 83, 249-261, 2009.

Soudarin, L., Cretaux, J.F., Cazenave, A. Vertical crustal motions from the DORIS space-geodesy system. Geophys. Res. Lett. 26, 1207-1210, 1999.

Tavernier, G., Fagard, H., Feissel-Vernier, M., Le Bail, K., Lemoine, F., Noll, C., Noomen, R., Ries, J.C., Soudarin, L., Valette, J.J., Willis, P. The International DORIS Service: genesis and carly achievements. $J$ Geod. 80, 403 417, 2006.

Testut, L., Wöppelmann, G., Simon, B., Téchiné, P. The sea level at Portaux-Français, Kerguelen Island, from 1949 to present. Ocean Dynamics 56, 464 472, 2006.

Vignudelli, S., Cipollini, P., Roblou, L., Lyard, F., Gasparini, G.P., Manzella, G., Astraldi, M. Improved satellite altimetry in coastal systems: case study of the Corsica Channel. Geophys. Res. Lett. 32, L07608, 2005. von Storch, H., Zwiers, F.W. Statistical Analysis in Climate Research. Cambridge Univ. Press, 484 pp., 1999

Vignudelli, S., Kostianoy, A., Cipollini, P., Benveniste, J. (Eds.), Coastal Altimetry, Springer-Verlag, in press; 2010.

Williams, S.D.P., Willis, P. Error analysis of weekly station coordinates in the DORIS network. J. Geod. 80, 525-539, 2006.

Willis, P., Ries, J.C., Zelensky, N.P., Soudarin, L., Fagard, H., Pavlis, E.C., Lemoine, F.G. DPOD2005: an extension of ITRF 2005 for precise orbit determination. Adv. Space Res. 44, 535-544, 2009.

Willis, Boucher, C., Fagard, H., et al. Contributions of the French Institut Gcographique National (IGN) to the International DORIS ScrviceAdv. Space Res. 45, 1470-1480, 2010.

Woodworth, P.L. Have there been large recent sea level changes in the Maldive Islands? Global Planet. Change 49, 1-18, 2005.

Woodworth, P.L. Some important issues to do with long-term sea level change. Phil. Trans. R. Soc. A364, 787-803, 2006.

Woodworth, P.L., Vassic, J.M., Spencer, R., Smith, D.E. Precise datum control for pressure tide gauges. Marine Geod. 19, 1-20, 1996.

Wöppelmann, G., Letetrel, C., Santamaria, A., Bouin, M.N., Collileux, X., Altamimi, Z., Williams, S.D.P., Martin Miguez, B. Rates of sealevel change over the past century in a geocentric reference frame. Geophys. Res. Lett. 36, L12607, 2009.

Zlotnicki, V., Desai, S. Assessment of the Jason microwave radiometer's measurement of wet tropospheric path delay using comparisons to SSM/I and TMI. Marine Geod. 27, 241-253, 2004. 